\title{
Connecting Cross-sector Community Voices: Data, Disadvantage, and Postdigital Inclusion
}

\section{Sarah Hayes $^{1} \mathbb{D} \cdot$ Stuart Connor $^{1} \cdot$ Matt Johnson $^{1} \cdot$ Michael Jopling $^{1}$}

Accepted: 22 July 2021 / Published online: 3 August 2021

(c) The Author(s), under exclusive licence to Springer Nature Switzerland AG 2021

Keywords Postdigital inclusion · Human-data interaction · Digital divide · Postdigital positionality $\cdot$ Cross-sector voices $\cdot$ Postdigital knowledge exchange

\section{The Digital Divide, Data, and Disadvantage}

The often discussed 'digital divide' (Van Dijk 2020) between those who can benefit from the digital age, and those who cannot, is generally perceived as an issue of access to infrastructure and digital devices. When followed by an emphasis on digital skills training for those who have been disadvantaged, exactly how individuals encounter, create, or respond to data, or indeed how they resist the collection of data about themselves, is rarely mentioned. For example, a recent UK House of Lords report, 'Beyond Digital: Planning for a Hybrid World' (Marston et al. 2021), examines the complex implications of the Covid-19 pandemic on economic and social wellbeing. Whilst human digital interactions are acknowledged in the report as diverse, hybrid, or postdigital in nature, data tends to be mentioned in relation to research and statistical variation of access to services, or with regard to cyberattacks, or general loss of data. Yet data takes many different forms in postdigital society, and all of these are relevant, in matters of digital inequality and disadvantage.

Sarah Hayes

sarah.hayes@wlv.ac.uk

Stuart Connor

stuart.connor@wlv.ac.uk

Matt Johnson

m.johnson14@wlv.ac.uk

Michael Jopling

m.jopling@wlv.ac.uk

1 University of Wolverhampton, Wolverhampton, UK 
In our forthcoming Springer book, ${ }^{1}$ what we think of as 'data', and what it means for each of us to be recorded by it, to generate it and to interact with it, is shown to be a crucial part of any cross-sector debate concerning digital inclusion. This is particularly important too given the intimate relations that data-driven technologies, Artificial Intelligence (AI), the Internet of Things (IoT), algorithmic culture, facial recognition systems (Ada Lovelace Institute 2019), and wearable technologies have now assumed in our lives and learning, either with or without, our consent. Whether this concerns software code, data analytics, social media interactions, or other infrastructures involving data of some sort, these have 'become inseparable from policy processes and modes of governance' (Williamson 2019, 2020). During the Covid-19 pandemic lockdowns of 2020/2021, much additional online activity, tracking systems and applications, have added extra complexity too. In many policies though, facts and figures concerning matters of digital inclusion may be referred to as data, but they do not illuminate the complex forms that data now takes. Nor do they address the diverse and unequal ways in which people have capacity to interact with, or understand their relations with, data.

Having identified these issues, there is no quick remedy for one group of scholars, digital entrepreneurs, charitable agencies, or policy makers to address them alone. Research into the automation of digital poverty management has already demonstrated frightening, life threatening impacts for the vulnerable, from algorithmic decisions in data-driven eligibility systems and predictive models, to poor privacy and data security, or infringement of rights via surveillance (Eubanks 2018: 11). The 'digital poorhouse' described by Eubanks refers to the automation of decision making about access to services for the disadvantaged in society, where shared social decisions instead become 'systems engineering problems' (Eubanks 2018: 12). Yet even in discussing powerful analogies between public assistance programmes that have moved 'from poorhouse to database' (Eubanks 2018: 14), the emphasis is on how data gathered on people's circumstances is being managed. How each of us are managing data ourselves, to interact with it in every shape and form, remains under-explored.

The relatively new field of Human-Data Interaction (HDI) was proposed in order to 'open up a dialogue amongst interested parties in the personal and big data ecosystems' (Mortier et al. 2014). Intended to offer a framework for more meaningful relationships with data, it was designed by these authors primarily to guide the practices of those who are developing data-intensive systems. Comprising of three

\footnotetext{
1 In a new book soon to be published in the Postdigital Science and Education book series, HumanData Interaction, Disadvantage and Skills in the Community: Enabling Cross-Sector Environments for Postdigital Inclusion, Hayes, Connor, Johnson and Jopling (forthcoming 2022) will facilitate as editors a bottom-up, cross-sector contribution to collective knowledge about Human-Data Interaction (HDI) and postdigital inclusion. Rather than simply examining and commenting on a top-down framework, the contributions to this book will expand how HDI is perceived in very diverse settings. It will thus develop the existing HDI tenets of legibility, agency, negotiability, and resistance, through what is happening at a grass roots level. When none of us can escape the dynamic flows of data about us, or control what happens to data created by us, the experiences of both vulnerable groups and the cross-sector agencies who support them need to be heard, as they cannot be captured in static policy documents alone.
} 
key tenets: agency, legibility, negotiability, the HDI framework is intended to be sensitive to the socially situated nature of data and data-driven systems (Mortier et. al. 2014). The theme of resistance was recently introduced too for additional exploration. There are though some issues to consider, if HDI is to be helpful in agendas aimed at addressing the digital divide.

Firstly, whilst the HDI framework has challenged technology designers to confront the task of building more ethical systems, the key tenets within the framework still originate from a largely Computer Science disciplinary focus. We perceive a need to broaden the disciplines that engage with HDI and to bring their contributions into dialogue with agencies in the community that are working with disadvantaged individuals to address digital inclusion. Secondly, there can be an expectation that if a theory-led disciplinary framework exists, then this simply informs the direction of future policy and practice concerning data-driven systems. This though tends to overlook diverse 'postdigital positionalities' (Hayes 2021) of individuals and their contexts in a top-down approach. An alternative way to view human-data relations is to expand the HDI framework via real grassroots examples. This bottomup approach disrupts a systems engineering focus alone on data management, with a view instead towards data empowerment.

In the sections to come, we explore how such an approach might be developed. Initially, we provide some examples of the many expressions that data now seems to take in our lives, in order to illustrate just how elusive, the term itself can be. It is important, if we are to expand ideas about HDI, that we ask the question: In human-data interaction, what exactly are we interacting with? This opens a debate that is much broader than fairness of access to services through computer systems that gather our data, and algorithms that decide who gets what. It is a debate that concerns a larger 'postdigital dialogue' (Jandrić et. al 2019) in the community about how humans recognise and interact with the data they are creating in physical and virtual spaces, as well as their rights in relation to data created about them. We therefore raise the topic of enabling cross-sector environments, where such debate might take place, in order to further postdigital inclusion.

Whilst much is currently discussed concerning digital inclusion, to increase the access of citizens to digital services and devices, postdigital inclusion expands these arguments to take into account the messy, hybrid lives of postdigital citizens. Data does not sit neatly in spreadsheets and computer systems alone, it is a shadowy actor in our lives wherever we go, regardless of whether we use digital devices or not. Expanding the existing HDI framework with rich, diverse, cross-sector opinions and interdisciplinary theory is one way to further postdigital inclusion. It also demonstrates a form of postdigital knowledge exchange in action that informs policy based on activities in local communities. It is not often that both powerful, cross-sector activity and interdisciplinary academic debate take place together, to co-inform theoretical frameworks. Yet this is crucial now, given that across all disciplines there are critical, emerging (and sometimes converging) issues surrounding humans and the data they generate directly, or that is generated in relation to them, and their activities.

We conclude therefore that taking a conceptual framework and simply utilising it inform policy and/or practice is not enough in the case of human interactions with data. This assumes the theoretical framework is being applied to something static. 
What is needed instead are new ways to capture what is being learned in communities where the role of data in the digital divide is being addressed in ways that empower individuals. Finding routes to channel this cross-sector learning back into developing the HDI framework acknowledges the complexity of the data ecosystem, as we seek to collectively further postdigital inclusion.

\section{Diverse Expressions of Data in Postdigital Society}

Data is an abstract term that now refers to many intangible forms of information and knowledge that are generated both online and offline. Therefore, as discussed above, we do need to ask: In human-data interaction (HDI), what exactly are we interacting with? We also need to ask though: In HDI, what are we not interacting with? This is not simply about who does or does not have online access, it also concerns the unseen forms of discrimination that are now possible even when people have no computer interactions themselves. To briefly list some of the many expressions that data now takes in our lives helps to illustrate why an ongoing 'postdigital dialogue' (Jandrić et. al 2019) is needed in relation to HDI and human rights.

\section{Data About People}

Since early 2020, the Covid-19 global pandemic has highlighted acute and widespread inequalities that a digital divide reinforces amongst those who are already disadvantaged (UK Parliament 2020). Data about people on the Good Things Foundation (2021) website reminds us that during 2020, 3.7 billion people were digitally excluded worldwide (International Telecommunication Union 2020), an estimated 9 million people in the UK (16\%) were unable to use the Internet or their devices without assistance, and around 6.5 million in the UK (12\%) cannot open apps. Furthermore, two-thirds $(66 \%)$ of those online in the UK have not used the Internet or digital apps to manage their health and 13 million people in the UK lack the digital skills they need for work (Lloyds Bank UK CDI 2020).

Such broad facts and figures provide one form of data that illustrates the sheer scale of digital exclusion. Further questions then need to be explored though to understand what this means in people's lives, for their positionality in postdigital society (Hayes 2021), as they seek to 'build capacity, capability, and confidence' in accessing digital services (Tin Smart Social 2020). From the point of view of human rights, this data helps to emphasise that the 'digitally excluded also lack a voice and visibility in the modern world, as government services and democracy increasingly move online' (Good Things Foundation 2021). This raises the issue of more hidden forms of data about individual citizens that is now collected in digital systems, whether they themselves interact online, or not. 


\section{Data Poverty}

Other digital inequalities linked to data occur in the economic choices that individuals need to make with regard to maintaining any presence online. In a Nesta and Y Lab report, 'What is Data Poverty?', the authors address the issue of 'those individuals, households, or communities who cannot afford sufficient, private, and secure mobile or broadband data to meet their essential needs' (Lucas, Robinson, and Treacy 2020). This use of the term 'data' alongside 'poverty' refers to a practical, but also a complex issue, where matters of affordability, infrastructure, choices, privacy and security, quantity, skills, and usability may all play a part in households becoming 'data poor' (Lucas, Robinson and Treacy 2020: 5).

\section{The ‘Datafication’ Of Health}

In a recent report from the Ada Lovelace Institute, 'The data will see you now' (2020), the 'datafication' of health is examined along with its impacts on individuals and social wellbeing. Now that data concerning people's health is no longer confined to medical records and clinical trials but is gathered by wearable technologies and smartphone apps, there are new and 'significant consequences for people and society' (Ada Lovelace Institute 2020). Many societal and ethical challenges arise from a 'blurring of the boundaries of health data', and it is necessary to examine 'the mechanisms through which datafication occurs and how people's health becomes 'legible' to an array of actors' and how datafication challenges existing practical, legal and conceptual definitions of what counts as 'health data' (Ada Lovelace Institute 2020). From a Fitbit watch or ring, or any other form of wellness tracker that provides health information on the physical steps we take, to other forms of measuring what we do in terms of 'digital footprints', postdigital data of different hybrid forms is generated.

\section{Data Footprints Generated by Individuals and Companies}

The idea of a digital footprint or a digital shadow has circulated for some time, referring to an individual or a company's traceable digital activities, actions, and communications that manifest on the Internet or on digital devices. Detailed logs of our web history, responses to cookies, and clickbait, as well as what we buy, comments we post, and images we upload leave trails that reveal our behavioural preferences. Online mapping tools can 'scrape' our digital footprints to trace us, target us, and follow our every move across systems, servers, and cloud computing services. Data footprints made by companies can also require considerable infrastructure to manage, meaning that even small businesses can risk taking too short-term a view on data and its implications (T_HQ 2021). 


\section{Data That Tells Lies}

Whether communicated from person to person, or mediated via digital systems, we all rely on knowledge we can trust to enable us to make informed judgements. Yet, what if the data we trust has been cultivated to deliberately mislead, or is simply wrong, yet important decisions are made based on it? There is increasing concerns that fake news in online platforms such as Google, YouTube, Twitter, Facebook, Tik Tok, and many others with global reach 'is undermining the legitimacy of the press, the democratic process, and the authority of sources such as science, the social sciences and qualified experts' (MacKenzie and Bhatt 2020).

\section{Data, Disadvantage and Digital Skills}

Though efforts to provide digital skills training to improve opportunities for people in local communities have increased, the standards or frameworks these subscribe to are broad and variable. The DQ Institute (2021) discusses the need to develop personal 'digital intelligence' which 'represents critical skills needed to thrive in the digital age'. There are though many challenges arising in trying to provide the right levels of digital literacy, skills, and readiness for diverse individuals to apply to improve their life chances (Connor et al. 2019).

In our recent collaborative, exploratory regional project funded by the Engineering and Physical Sciences Research Council under the Learning, Skills and Social Justice theme of the HDI Network Plus, ${ }^{2}$ we opened a postdigital debate in the community ${ }^{3}$ concerning how awareness of Human-Data Interaction (HDI) and responses to data, fit into regional digital skills plans (Education Observatory 2020-2021). Through our interaction with grassroots networks and a cross-sector Digital Inclusion Coalition, as well as an analysis of existing approaches and policies, we identified a persistent gap in initiatives and regional digital roadmaps, where the HDI tenets as well as the individual 'postdigital' contexts of people's lives, are not visibly addressed.

For example, a provision of laptops or schemes to support data poverty, or increase skills for employability, do not seem to extend to addressing how people develop agency in relation to their data, or how legibility or negotiability will be improved. There is little evidence either of forms of resistance being acquired in relation to personal data and human rights, despite a multi-agency approach on furthering digital inclusion (The State of Data, 2020). Regional plans for 'digital upskilling' are aimed at local people who are already disadvantaged. Therefore, it is a problem if digital training and support intended to develop their employment do not also develop their agency to make choices and negotiate legitimate use of their data. It is an issue if the HDI tenets are not addressed to help people to respond to data-related inequities and make empowered personal decisions.

\footnotetext{
2 See https://hdi-network.org/about/. Accessed 22 July 2021.

${ }^{3}$ See https://educationobservatory.co.uk/human-data-interaction/. Accessed 22 July 2021.
} 


\section{Debate That Connects Community Voices Can Be Written as Well as Spoken}

The nature of debate is that diverse voices and real-life experiences might be heard, and responded to, as opposed to reports containing generalised notions of what might work in diverse communities. This is particularly important when entrenched inequalities are affecting people in different ways across local regions (Hayes et al. 2020), even before digital solutions are introduced to try to help. The Covid-19 pandemic has revealed many additional complexities concerning the deeply contextual nature of digital disadvantage both internationally and locally (Traxler et al. 2020) and has demonstrated why 'positionality' matters (Hayes 2021) when examining the hybrid and messy 'postdigital' nature of human lives (Jandrić et al. 2018).

We tend to think of a debate as spoken, but it can be equally powerful for debate to take place in a written format, such as an edited collection. Often edited collections are books that are compiled from isolated, independent chapters, routinely brought together by editors through a summary of contents. They can thus become little more than a vehicle of 'standardised production, within our neoliberal political economy' (Peters et al. 2021). Those who contribute are frequently all from academic institutions, and such volumes may then lack the insights that local businesses, charities, councils, creative agencies, coalitions, or other individuals and regional groups might offer. Yet with universities increasingly playing a key part in the regeneration of the cities in which they are based, their civic role and engagement with local authorities and industrial strategy for economic and social wellbeing have become increasingly important (University Partnerships Programme Foundation 2019; Jopling and Johnson 2019).

\section{Enabling Cross-sector Environments for Postdigital Knowledge Exchange}

Expanding the existing HDI framework with rich, diverse, cross-sector opinions and interdisciplinary theory is one way to begin to further postdigital inclusion, via a form of postdigital knowledge exchange. Rather than heading into the community with a ready-made policy model or knowledge exchange framework to work to, postdigital knowledge exchange disrupts and inverts this approach. Based on both cross-sector postdigital dialogue and interdisciplinary academic debate together, these co-inform more dynamic theoretical and policy frameworks. This approach underpinned our forthcoming book in the Postdigital Science and Education series ${ }^{4}$ : Human-Data Interaction, Disadvantage and Skills in the Community: Enabling Cross-Sector Environments for Postdigital Inclusion.

Behind terms like 'digital divide', digital participation', and 'digital literacy' is the closely related issue of data, and the numerous and confusing ways in which

\footnotetext{
4 See https://www.springer.com/series/16439. Accessed 22 July 2021.
} 
it might be understood. Data receives little attention in generic digital access and skills plans, yet it is a topic that has far reaching implications for all of us, whether in education, health, local industries, or social inclusion agendas, in physical spaces and online settings. Whilst our efforts provide one way to develop an enabling cross-sector environment to explore the challenges and creative solutions being developed out in the wider community for HDI, skills, and postdigital inclusion, the ongoing challenges of personal data management (Mortier et al. 2020) need to be explored from many angles and disciplines.

\section{Contributing to the Human-Data Interaction Framework}

The topic of Human-Data Interaction (HDI) places the human at the centre of the numerous data flows that systems of all kinds, and people interacting with themknowingly or not, now generate (Victorelli et al. 2020). Given the accelerating trends towards ubiquitous and pervasive computing activities in or about people's lives, HDI provides a basic framework through which the lived experiences of human beings and their encounters with data might be examined. The HDI framework currently consists of the following four areas of exploration:

Legibility: enhancing the comprehensibility of data about people or datadriven systems.

Agency: empowering the individual to act in response to actions made on their personal data.

Negotiability: influencing others' use of one's data, thereby enhancing one's control over it.

Resistance: studies where resistance is being developed in any area of data interactions.

This framework can begin to help us to better understand how our behaviours, the data our behaviours generate, and the algorithms which process these data, increasingly shape our lives, including introducing integral forms of bias (Mortier et al. 2020). What the current framework lacks though is the intimate and diverse cases drawn from the community of people's lived experiences that will develop it further. This includes hearing from the initiatives that are being developed in relation to postdigital inclusion that will provide a lens to better understand how data and disadvantage might be addressed. Whilst many of us may not need to interact with very large quantities of data, it is now very unclear (given even some of the categories discussed above) as to what exactly constitutes data on or about us, and importantly how it is being used.

Data now shapes our behaviours and opportunities and as such it shapes our lives. Amid such a complex ecosystem, the multi-disciplinary field of HumanData Interaction (HDI) is one route through which we might respond by placing human beings at the centre of all types of data flows. The HDI framework is concerned with providing a transparent mechanism for people to interact explicitly with the systems and data they encounter and generate. 


\section{Conclusions}

For decades now, governments, local and international authorities, companies, charitable agencies, educational bodies, and individuals have sought to address a 'digital divide'. However, in the postdigital lives that humans now lead, data takes countless forms, with the impact from data-driven technologies now being realized in education, health, industries and businesses, social inclusion, and many other aspects of life in both physical spaces and online settings. We have argued for an exploration of the challenges and creative solutions that are being developed out in the wider community as a basis for extending our understanding of HDI. By inviting widely inclusive cross-sector postdigital participation, partnership, and collaboration to address any aspects of HDI, we can build new forms of postdigital knowledge exchange. At a time when universities are expected to demonstrate external engagement and respond to frameworks concerning knowledge transfer, there is an opportunity to develop more powerful forms of knowledge exchange that benefits postdigital citizens.

Simply taking a conceptual framework and utilising it inform policy and/or practice is no longer feasible in the case of human interactions with data in postdigital society. People's positional experiences of interaction with data are not static, and therefore, our theoretical and policy frameworks cannot remain static either. What is needed instead are new ways to capture what is being learned in communities where the role of data in the digital divide is being addressed. Finding routes to channel this cross-sector learning through postdigital knowledge exchange back into developing the HDI framework acknowledges the complexity of the data ecosystem, as we seek to collectively further postdigital inclusion.

\section{References}

Ada Lovelace Institute (2019). Beyond face value: public attitudes to facial recognition technology. https://www.adalovelaceinstitute.org/case-study/beyond-face-value/. Accessed 20 June 2021.

Ada Lovelace Institute (2020). The data will see you now. https://www.adalovelaceinstitute.org/project/ boundaries-of-health-data/. Accessed 25 June 2021.

Connor, S., Mahoney, M., \& Lewis, N. (2019). Anticipating a $4^{\text {th }}$ Industrial revolution and the futures of learning: a discussion paper for Wolverhampton Learning City Region. https://wlv.openrepository. com/bitstream/handle/2436/622286/Connor_et_al_Anticipating_2019.pdf?sequence=1\&isAllowed=y. Accessed 25 June 2021.

DQ Institute. (2021). What is the DQ Framework? Global Standards for Digital Literacy Skills and Readiness. https://www.dqinstitute.org/global-standards/\#contentblock1. Accessed 30 June 2021.

Education Observatory (2020-2021). Data and disadvantage: taking a regional approach towards human data interaction (HDI). https://educationobservatory.co.uk/human-data-interaction/. Accessed 29 June 2021.

Eubanks, V. (2018). Automating inequality. How high-tech tools profile, police, and punish the poor. New York: St. Martin's Press.

Hayes, S. (2021). Postdigital Positionality: developing powerful inclusive narratives for learning, teaching, research and policy in HE. Leiden: Brill.

Hayes, S., Jopling, M., Hayes, D., Westwood, A., Tuckett, A., \& Barnett, R. (2020). Raising regional academic voices (alongside data) in Higher Education (HE) debate. Postdigital Science and Education, 3(1), 242260. https://doi.org/10.1007/s42438-020-00131-6. 
International Telecommunication Union. (2020). Digital inclusion of all. https://www.itu.int/en/mediacentre/ backgrounders/Pages/digital-inclusion-of-all.aspx. Accessed 19 July 2021.

Jandrić, P., Knox, J., Besley, T., Ryberg, T., Suoranta, J., \& Hayes, S. (2018). Postdigital Science and Education. Educational Philosophy and Theory, 50(10), 893-899. https://doi.org/10.1080/00131857.2018. 1454000.

Jandrić, P., Ryberg, T., Knox, J., Lacković, N., Hayes, S., Suoranta, J., Smith, M., Steketee, A., Peters, M. A., McLaren, P., Ford, D. R., Asher, G., McGregor, C., Stewart, G., Williamson, B., \& Gibbons, A. (2019). Postdigital Dialogue. Postdigital Science and Education, 1(1), 163-189. https://doi.org/10. 1007/s42438-018-0011-x.

Jopling, M., \& Johnson, M. (2019). Black Country Education Insight Report 2019. http://educationobservatory. co.uk/edobs/wp-content/uploads/2020/02/Black-country-Annual-Education-Insight-Report-050219.pdf.

Lloyds Bank UK Consumer Digital Index (CDI) (2020). https:/www.lloydsbank.com/assets/media/ pdfs/banking_with_us/whats-happening/210519-1loyds-cdi-2020-updated-report.pdf. Accessed 19 July 2021.

Lucas, P. J., Robinson, R., \& Treacy, L. (2020). What Is Data Poverty? Nesta. https://media.nesta.org.uk/ documents/What_is_Data_Poverty.pdf. Accessed 25 June 2021.

MacKenzie, A., \& Bhatt, I. (2020). Lies, Bullshit and Fake News. Postdigital Science and Education, 2(1), 1-8. https://doi.org/10.1007/s42438-019-00085-4.

Marston, H., Wilson, G., Morgan, D. J., \& Gates, J. (2021). Beyond Digital: Planning for a Hybrid World. Covid-19 Committee: 1st Report of Session 2019-21, (HL 263). http://oro.open.ac.uk/ 76051/1/UKCommittee_report.pdf. Accessed 27 June 2021.

Mortier, R., Haddadi, H., Henderson, T., McAuley, D., \& Crowcroft, J. (2014). Human-data interaction: The human face of the data-driven society. https://arxiv.org/pdf/1412.6159.pdf. Accessed 24 June 2021.

Mortier, R., Haddadi, H., Henderson, T., McAuley, D., Crowcroft, J., \& Crabtree, A. (2020). Human-data interaction. In M. Soegaard \& R. F. Dam (Eds.), The Encyclopaedia of Human-Computer Interaction, $2^{\text {nd }}$ Edition. Interaction Design Foundation.

Peters, M. A., Jandrić, P. \& Hayes, S. (2021). Revisiting the Concept of the 'Edited Collection': Bioinformation Philosophy and Postdigital Knowledge Ecologies. Postdigital Science and Education, 3(2), 383-393. https://doi.org/10.1007/s42438-021-00216-w.

T_HQ (2021). What do you know about your data footprint? https://techhq.com/2018/11/what-do-youknow-about-your-data-footprint/. Accessed 27 June 2021.

The Good Things Foundation (2021). The Digital Divide. https://www.goodthingsfoundation.org/thedigital-divide/. Accessed 20 June 2021.

The State of Data (2020). Report: mapping children's data in state education in England (2020) defenddigitalme. https://defenddigitalme.org/the-state-of-data-2020/. Accessed 24 June 2021.

Tin Smart Social (2020). Platform for Digital Skill Enhancement. https://www.tinsmartsocial.com/about. Accessed 27 June 2021.

Traxler, J., Scott, H., Smith, M., \& Hayes, S. (2020). Learning through the crisis Helping decision-makers around the world use digital technology to combat the educational challenges produced by the current COVID-19 pandemic (No. 1). Wolverhampton: University of Wolverhampton, EdTech Hub. https://docs. edtechhub.org/lib/CD9IAPFX/download/5N87EV2E/TraxlerLearningthroughthecrisisHelpingdecisionmaker.pdf. Accessed 26 June 2021.

UK Parliament (2020). COVID-19 and the digital divide. https://post.parliament.uk/covid-19-and-thedigital-divide/. Accessed 30 June 2021.

University Partnerships Programme Foundation. (2019). Truly civic: strengthening the connection between universities and their places. https://upp-foundation.org/wp-content/uploads/2019/02/ Civic-University-Commission-Final-Report.pdf. Accessed 26 June 2021

Van Dijk, J. (2020). The digital divide. Cambridge, UK: Polity.

Victorelli, E. Z., Dos Reis, J. C., Hornung, H., \& Prado, A. B. (2020). Understanding human-data interaction: Literature review and recommendations for design. International Journal of Human-Computer Studies, 134, 13-32. https://doi.org/10.1016/j.jhcs.2019.09.004.

Williamson, B. (2019). Digital policy sociology: software and science in data-intensive precision education. Critical Studies in Education, 62(3), 354-370. https://doi.org/10.1080/17508487.2019.1691030.

Williamson, B. (2020). New pandemic edtech power networks. https://codeactsineducation.wordpress. com/2020/04/01/new-pandemic-edtech-power-networks/. Accessed 26 June 2021. 